\title{
Observatório
}

ISSN n² 2447-4266

Vol. 4, n. 1, Janeiro-Março. 2018

DOI: http://dx.doi.org/10.20873/uft.2447-4266.2018v4n1p599

\section{O CASO ELIZA SAMÚDIO COMO ACONTECIMENTO: fama, anonimato e a violência de gênero em nossa sociedade}

THE CASE ELIZA SAMÚDIO FROM THE PERSPECTIVE OF THE EVENT: fame, anonymity and gender violence in our society

EL CASO ELIZA SAMUDIO COMO UN ACONTECIMIENTO: fama, anonimato y violencia de género en la sociedad

\section{Paula Guimarães Simões ${ }^{1}$ Laura Antônio Lima ${ }^{2,3}$}

\section{RESUMO}

O artigo analisa o caso do desaparecimento/assassinato de Eliza Samúdio a partir da perspectiva teórica do acontecimento (QUÉRÉ, 2005, 2012). Buscamos perceber 0 processo de individuação dessa ocorrência através de três

\footnotetext{
${ }^{1}$ Doutora, mestre e graduada em Comunicação Social pela Universidade Federal de Minas Gerais (UFMG). Professora Adjunta do Departamento de Comunicação Social da Universidade Federal de Minas Gerais (UFMG) e Professora Permanente do Programa de Pós-Graduação em Comunicação (PPGCOM/UFMG). E-mail: paulaguimaraessimoes@yahoo.com.br.

2 Mestranda em Comunicação Social pela Universidade Federal de Minas Gerais (DCS/FAFICH/UFMG). Possui graduação em Ciências Sociais pela mesma instituição. Atualmente é bolsista CAPES no mestrado e integrante do GRIS - Grupo de Pesquisa em Imagem e Sociabilidade (DCS/UFMG). E-mail: lauraantoniolima@gmail.com.

3 Endereço de contato das autoras (por correio): Universidade Federal de Minas Gerais, Faculdade de Filosofia e Ciências Humanas, Departamento de Comunicação Social, Pampulha, CEP: 31270-901 - Belo Horizonte, MG - Brasil.
} 


\section{Obsisto}

ISSN n² 2447-4266

Vol. 4, n. 1, Janeiro-Março. 2018

DOI: http://dx.doi.org/10.20873/uft.2447-4266.2018v4n1p599

categorias de análise: a descrição, a narração e o contexto de fundo. Entendemos que, ao ganhar individualidade, o acontecimento revela sentidos e valores da sociedade em que se inscreve, além de iluminar problemas que podem estar invisíveis. Através de um corpus de 200 textos (notas, reportagens, cartas do leitor) dos jornais $O$ Globo e Folha de S. Paulo, procuramos também observar as articulações entre os eixos da realidade da morte, da violência de gênero e da oposição anonimato/fama.

PALAVRAS-CHAVE: Eliza Samúdio; Acontecimento; Fama; Morte; Gênero.

\section{ABSTRACT}

This paper aims at analyzing Eliza Samúdio missing/murderer using the event theoretical perspective, especially Louis Quéré $(2005,2012)$ concepts. Through three categories of analysis: description, narration and background context, the goal is comprehend the individuation process, because when an event gains individuality, it reveals values and senses of society, and can show invisible problems. It aims, also, at observing links between gender violence, fame/anonymity opposition and the reality of death throughout 200 texts of two Brazilian newspapers O Globo and Folha de S. Paulo.

KEYWORDS: Eliza Samúdio; Event; Fame; Death; Gender.

\section{RESUMEN}

El artículo analiza el caso de la desaparición/asesinato de Eliza Samudio desde la perspectiva teórica del acontecimiento (QUÉRÉ, 2005, 2012). Se busca entender el proceso de individuación de este evento a través de tres categorías de análisis: descripción, narración y fondo pragmático. Entendemos que, al ganar individualidad, el evento revela significados y valores de la sociedad en la que se incluye, además deaclarar cuestiones que pueden estar invisibles en ella. A través de un corpus de 200 textos (notas, reportajes, cartas de los lectores) de los periódicos O Globo y Folha de S.Paulo, se intentó 


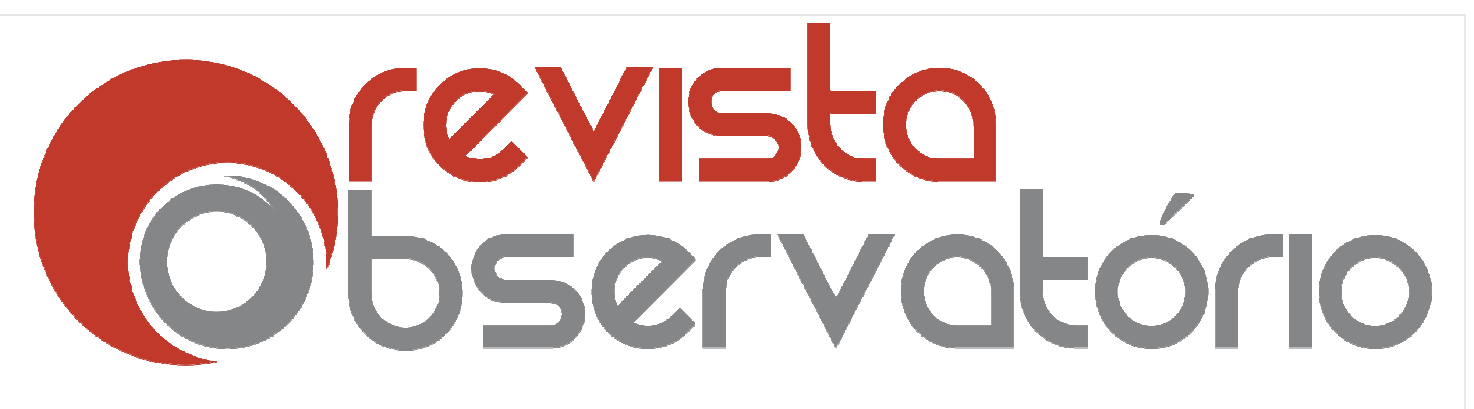

ISSN n² 2447-4266

Vol. 4, n. 1, Janeiro-Março. 2018

DOI: http://dx.doi.org/10.20873/uft.2447-4266.2018v4n1p599

observar las articulaciones entre los ejes de la realidad de la muerte, la violencia de género y de la oposición anonimato/fama.

PALABRAS CLAVE: Eliza Samudio; Evento; Fama; Muerte; Género.

Recebido em: 28.02.2017. Aceito em: 20.11.2017. Publicado em: 01.01.2018. 


\section{Observatório}

ISSN n² 2447-4266

Vol. 4, n. 1, Janeiro-Março. 2018

DOI: http://dx.doi.org/10.20873/uft.2447-4266.2018v4n1p599

\section{Introdução}

Eliza Samúdio era uma mulher de 25 anos quando desapareceu sem deixar rastros em Minas Gerais. A busca pelo seu paradeiro iniciou-se no fim de junho de 2010 juntamente com uma investigação sobre seu último companheiro, o então goleiro do Flamengo, Bruno Fernandes. Ao longo da investigação, o desaparecimento pouco a pouco foi transformando-se em morte e assassinato. Em julho de 2015, mais duas pessoas foram envolvidas no julgamento do caso (RUBENS, 2015), que condenou várias pessoas. Em 2017, as notícias envolvendo Bruno falavam de sua reabilitação em uma Apac, alternativa aos presídios tradicionais, a qual busca um espaço menos degradante, alicerçado na comunidade e no trabalho de cada um dos detentos para a manutenção do espaço.

Por que analisar esse acontecimento? Em primeiro lugar, ele chama a atenção para uma entre várias mulheres que sofrem violência doméstica, relacionamentos abusivos e machismo diariamente - desvelando um problema público que precisa ser enfrentado em nossa sociedade. A jovem denunciou Bruno antes de desaparecer e, como acontece muitas vezes, sua denúncia foi ignorada. Em segundo lugar, essa ocorrência ajuda a refletir sobre a relação entre $\mathrm{o}$ anonimato e a fama que nos parece reveladora sobre a sociedade em que vivemos. Afinal, "todos querem escapar do anonimato, todos querem se singularizar, seja como fã [...] ou como ídolo" (HERSCHMANN; PEREIRA, 2003, p.12). E, em terceiro lugar, esse acontecimento auxilia a pensar na realidade da morte e no modo como a mídia e a sociedade lidam com ela. Apesar de o corpo de Eliza não ter sido encontrado até o momento, seu falecimento foi declarado na mídia. Segundo Herschmann e Pereira, eventos da vida humana como doenças, loucura e morte não são mais vividos socialmente, essas 


\section{Obevisto}

ISSN n² 2447-4266

Vol. 4, n. 1, Janeiro-Março. 2018

DOI: http://dx.doi.org/10.20873/uft.2447-4266.2018v4n1p599

experiências acabam "re-ritualizadas ao serem vivenciadas mediaticamente" (HERSCHMANN; PEREIRA, 2003, p.10).

A partir desses três eixos (a violência contra a mulher, o anonimato transformado em fama e a realidade da morte), tentamos perceber o poder hermenêutico desse acontecimento (QUÉRÉ, 2005). Ou seja, o que ele descortina sobre o lugar em que vivemos, o que ele pode revelar acerca de elementos constituidores de nossa sociedade.

Utilizando a cobertura jornalística do caso (detalhada posteriormente), analisamos tal ocorrência como um acontecimento, o qual mobiliza a opinião pública, gera debates e envolvimento da sociedade. Entendemos que a mídia e a sociedade estão intrinsecamente relacionadas, são espaços em que os acontecimentos não só são produzidos e reportados, mas também ganham sentido: "na medida em que vivemos uma experiência bastante midiatizada, os acontecimentos que aparecem na mídia ganham força no nosso cotidiano e em nossas conversações" (LEAL et al, 2010, p.207).

Assim, o artigo é iniciado com uma seção sobre a relação entre o anonimato e a fama, seguida de uma discussão acerca da morte e do acontecimento interligados. A partir desse referencial teórico, realizamos a análise do corpus coletado na seção seguinte. Por fim, retomamos os principais achados da investigação na seção final do artigo, evidenciando o poder hermenêutico do acontecimento em foco.

\section{Anonimato e fama}

As relações entre a fama e o anonimato são mais complexas do que poderíamos imaginar inicialmente. Vivemos em um momento de publicização da vida privada (com as redes sociais e selfies em profusão) em que muitas 


\section{Observatório}

ISSN n² 2447-4266

Vol. 4, n. 1, Janeiro-Março. 2018

DOI: http://dx.doi.org/10.20873/uft.2447-4266.2018v4n1p599

pessoas tentam alcançar seus 15 minutos de fama enquanto lutam no mundo dos anônimos. Rojek (2008) ilumina a questão ao dizer que há uma relação com a construção da vida pública, com a celebrificação das identidades e das interações sociais.

A celebrificação da vida pressupõe uma influência da cultura da celebridade nos aspectos mais diversos da personalidade, como a criação de uma identidade e no relacionamento com outras pessoas. É a inspiração, a encarnação de um modelo a seguir, de um tipo social. Além disso, Rojek diz que a cultura da celebridade se torna um polo de identificação e ancoragem, assumindo um papel de integração entre as pessoas. As celebridades também falam a um desejo abstrato e alienável, fruto da mercantilização de várias esferas da vida, incluindo dos sentimentos (ROJEK, 2008).

Na mesma linha, Lipovetsky e Serroy (2011, p. 83) falam sobre o movimento de celebrização que vai da estrela "pura" que carrega ideais de glória, eternidade, perenidade e chega às pessoas "celebrizadas", categoria em que Eliza poderia se situar. Esse grupo de conhecidos faz parte de uma indústria de revistas, jornais e blogs especializados em "cobrir" seus passos. São os anônimos e anônimas de ontem que finalmente conseguiram "virar notícia", mesmo que por um curto período de tempo e em situações trágicas como foi o caso aqui em análise. Os autores dizem que isso é possível em um mundo de pessoas, lugares e atividades estrelas: "O próprio mundo entrou no sistema da celebridade. O que não dá imagem e não é midiatizado não existe" (LIPOVETSKY; SERROY, 2011, p.83).

Dois exemplos dessa hierarquia de famas: Kim Kardashian, protagonista do reality show transmitido pelo canal E! Entertainment Television sobre a vida de sua família, foi a estrela do comercial da T-Mobile transmitido durante o 


\section{Orevisto}

ISSN n² 2447-4266

Vol. 4, n. 1, Janeiro-Março. 2018

DOI: http://dx.doi.org/10.20873/uft.2447-4266.2018v4n1p599

intervalo do Super bowl $l^{4}$. Ela é identificada como pessoa famosa ${ }^{5}$ porque sua fama não está associada a nenhum tipo de excelência ou habilidade específica. Ela pode ser definida a partir da clássica definição de Braudy, para quem "a celebridade é uma pessoa conhecida por ser bem conhecida" (1997, p. 57). Outro evento ocorreu no RockinRio de 2013, em que uma lista dos organizadores de um camarote classificou famosos entre "vipinho e "vipão". Ao ser divulgada, a lista virou notícia justamente por explicitar os diferentes graus de fama entre as celebridades.

O lugar do anonimato é, assim, um espaço quase desprezado na sociedade em que vivemos. Nesse contexto, é preciso situar a busca pela fama como catalizadora de reconhecimento, status e admiração. E por que ser desconhecido(a) é muitas vezes um sofrimento? De acordo com Andrea Vaz (2006), a realidade material é o que dá origem aos sentimentos de frustração: o sentir-se anônimo e não ter reconhecimento são impulsos para a frustração na contemporaneidade.

Segundo Herschmann e Pereira (2003), é dramático não fazer parte do filme-vida. Os autores recuperam Da Matta para lembrar o status de superpessoa que os(as) famosos(as) possuem no Brasil. A relação com o anonimato pode ser encarada quase como falta de dignidade, não ser famoso(a) está na fronteira com ser humilhado(a). Querer fazer parte desse grupo famoso é, de certa forma, querer fazer parte do discurso que produz

\footnotetext{
${ }^{4}$ Jogo final da temporada da NFL (liga de futebol americano dos EUA). É o evento mais assistido da tevê estadunidense, com anúncios milionários. Em 2015 aconteceu no dia 01 de fevereiro.

${ }^{5}$ Kim Kardashian era uma das pessoas mais seguidas no mundo no Instagram, com 22 milhões de seguidores.

6 Matéria disponível em <

http://celebridades.uol.com.br/noticias/redacao/2013/09/21/camarote-do-vipinho-e-vipao-dizque-nao-quis-diferenciar-convidados.htm >. Acesso em 25/03/2015, às 14h10min.
} 


\section{Observatório}

ISSN n² 2447-4266

Vol. 4, n. 1, Janeiro-Março. 2018

DOI: http://dx.doi.org/10.20873/uft.2447-4266.2018v4n1p599

significado sobre a vida da atualidade (REDMOND, 2006 apud PRIMO, 2011, p.165).

A celebrização de Eliza acontece durante a investigação de seu desaparecimento. No início das reportagens sobre o caso (final de junho de 2010), ela é citada como ex-namorada de Bruno, estudante que se envolveu com o goleiro, antes de ser propriamente nomeada. A última reportagem coletada do jornal Folha de S. Paulo, datada de 27 de agosto de 2010, já traz um cabeçalho intitulado "Caso Eliza", e o nome dela aparece seguido do aposto "ex-namorada" do jogador. A escrita das reportagens pode nos revelar uma sutil mudança na maneira de descrevê-la. O que observamos é um deslocamento de vítima com papel secundário na vida da estrela Bruno Fernandes para a de papel principal num crime.

A espetacularização do crime, a cobertura sensacionalista dos jornais e o bombardeamento do assunto pelos meios de comunicação contribuem para a celebrificação do momento e, consequentemente, para um reconhecimento dos envolvidos pela opinião pública. Este tipo de reconhecimento é um elemento essencial do fator celebridade, para Rojek (2008).

Dessa forma, consideramos Eliza uma figura pública. Sua associação com o jogador Bruno Fernandes gerava especulação, mas nada comparado ao escrutínio de sua vida pregressa feito pela mídia depois de seu desaparecimento. $O$ espaço de anônima aparentemente não era suficiente para Eliza, que desejava ser famosa e não imaginava o desfecho trágico dessa trama. Para analisar essa intriga, é preciso discutir a morte como um acontecimento, eixo que orienta a investigação aqui realizada. 


\section{Obevisto}

ISSN n² 2447-4266

Vol. 4, n. 1, Janeiro-Março. 2018

DOI: http://dx.doi.org/10.20873/uft.2447-4266.2018v4n1p599

\section{Acontecimento e morte}

O acontecimento pode ser conceituado como aquilo que irrompe em determinado contexto e instaura uma descontinuidade na experiência dos sujeitos. A palavra-chave experiência evoca as bases pragmatistas da teoria, que o concebe como "choques salutares, que desencadeiam reações positivas pelas quais aqueles que suportam o curso de ações e ocorrências retomam-nas em suas mãos" (FRANÇA; OLIVEIRA, 2012, p.9). Mas o que é, de fato, o acontecimento? Um fato jornalístico, algo reportado e noticiado pelos meios de comunicação, um evento grande e transformador? Um ponto na história de uma sociedade?

Um acontecimento pode ser entendido como "o que vem de fora, o que surge, o que acontece, o que se produz, o excepcional que se desconecta da duração" (QUÉRÉ, 2012, p.21). O acontecimento pode ser abordado através de múltiplas perspectivas. A que iremos nos ater é uma perspectiva que

localiza a força e a existência do acontecimento nos sujeitos, em sua disponibilidade/capacidade de percepção, e no poder constituinte da linguagem [...] [que busca] alcançar a articulação entre o potencial de afetação do real (do mundo das coisas concretas) e os sujeitos que se veem afetados, agem - e falam - em consequência. (FRANÇA, 2012, p.45)

E essa tentativa de articular a afetação do acontecimento com a ação/fala dos sujeitos afetados é justamente inscrever o acontecimento no domínio da experiência e ressaltar o seu poder hermenêutico. Afinal, o acontecimento deve ser capaz de revelar mais coisas do que apenas a descrição de um evento, como nos diz França (2012, p.48):

Ele descortina níveis velados da vida social, aponta possibilidades, suscetibiliza, mobiliza, provoca reações e mudanças. [...] acontecimentos são aquilo mesmo que conforma nossa experiência 


\section{Observatório}

ISSN n² 2447-4266

Vol. 4, n. 1, Janeiro-Março. 2018

DOI: http://dx.doi.org/10.20873/uft.2447-4266.2018v4n1p599

[e] revelam o tecido vivo da vida social. Eles não apenas fazem falar; eles colocam questões, revelam aspectos, abrem possibilidades.

A morte, como evento natural e irrepreensível da vida humana, tem potencial acontecimental, é reveladora sobre a sociedade a partir do momento em que é construída socialmente. Segundo Rocha e Santos (2013, p.13), "os vários sentidos de que temos sobre a morte também são constituídos através do caráter simbólico que moldam nossos corpos sociais, constantemente reelaborados pelos meios midiáticos e pela cultura da mídia".

A morte em si é individual, mas a maneira como a encaramos é social. A depender das práticas culturais, a relação com o morrer é completamente diferente, vide os exemplos do Dia dos Mortos no México, o uso da cor branca para simbolizar o luto dos hindus (e de outras religiões/regiões), o velório e o sepultamento, o ato de devorar a carne humana em algumas sociedades. Lidar com a morte é social.

É essa perspectiva da morte inscrita no social que nos interessa: olhar para as reverberações do acontecido no cotidiano, para os códigos e símbolos que usamos para tratar dele. Michel Vovelle (1987), através de uma tipologia da morte, desenvolve três níveis de análise sob uma perspectiva histórica: a morte consumada, a morte vivida e o discurso sobre a morte. O primeiro nível "é o fato bruto da mortalidade" (VOVELLE, 1987, p.130), são os dados demográficos, as mortes diárias, os parâmetros sociais desiguais das mortes nas sociedades. 0 segundo degrau na análise do autor é a "rede de gestos e ritos" (idem, 1987, p.131) desde a enfermidade até o processo funerário, que pode revelar uma "estrutura de sistemas", uma complexidade na articulação de códigos culturais a fim de conferir sentido ao que aconteceu. O terceiro e último nível, o discurso sobre a morte, mistura-se e se confunde com o segundo, mas podemos 


\section{Observatório}

ISSN n² 2447-4266

Vol. 4, n. 1, Janeiro-Março. 2018

DOI: http://dx.doi.org/10.20873/uft.2447-4266.2018v4n1p599

caracterizá-lo como uma consolidação coletiva daqueles ritos e gestos: é a experiência da morte apreendida pela sociedade. E é através desses discursos "que se pode acompanhar a evolução das representações do outro mundo, que prolongam e condicionam, para a maioria dos homens, o sistema global da morte e do após-morte" (idem, 1987, p.133).

A era moderna e suas características trouxeram mudanças ao tratamento da morte, consensualmente. Considerando nossa inserção em uma sociedade moderna individualista, as categorias de Vovelle acerca da morte vivida e do discurso sobre a morte são afetadas e passam a expor uma morte cada vez mais individualizada, medicalizada, solitária. Nesse contexto, onde está a sociabilidade da morte? Ou, como lidamos socialmente com a morte em uma sociedade individualista?

Hans Joas (2012) elabora uma tese sobre a sacralidade humana como fator de sustentação dos direitos humanos universais. Essa perspectiva ajuda a compreender a relação do individualismo com a morte. A modernidade traz indivíduos atomizados, inseridos em suas próprias narrativas e isolados, e Joas adiciona a esse processo outro movimento, a sacralização da pessoa:

a crença nos direitos humanos e na dignidade humana universal como
resultado de um processo específico de sacralização - processo
durante o qual cada ser humano individual, gradativamente e com
motivação e sensibilização cada vez mais intensas, foi passando a ser
entendido como sagrado, e essa compreensão foi institucionalizada
no direito. (JOAS, 2012, p19)

A ideia de sacralização não está exclusivamente relacionada à religião, como nos lembra o autor, mas mantém duas características de sacralidade: evidência subjetiva e intensidade afetiva. A personalidade, a pessoa, o corpo e a dignidade de cada um de nós seriam sagrados e, por isso, protegidos. É essa articulação de formação de uma categoria "pessoa" que dá o tom do 


\section{Observatório}

ISSN n² 2447-4266

Vol. 4, n. 1, Janeiro-Março. 2018

DOI: http://dx.doi.org/10.20873/uft.2447-4266.2018v4n1p599

individualismo. Apesar disso, mas talvez por causa disso, as experiências de morte continuem nos afetando. O morrer afeta a todos e a cada um. Mesmo que esse cada um seja "sagrado".

É pelo fato de a morte romper a ordem, trazer o inesperado, que ela suscita reações - como qualquer outro acontecimento. A morte como parte do que é a pessoa, mesmo estando no futuro, acaba fazendo parte do que são os limites da vida. Grandes e trágicos acontecimentos como quedas de aviões, desastres naturais ou ataques terroristas adicionam o fator imprevisibilidade ao grande número de pessoas que morrem nessas situações, mas mesmo na singeleza de uma pessoa, já pensamos sobre o fim de nossas vidas. A ideia da morte atua como um elemento definidor das possibilidades humanas. da própria ideia do que é estar vivo e de na nossa relação com o mundo:

Quando topamos com as nossas limitações e vivenciamos quão pouco podemos mudar o nosso destino ou o de outros ou quando radicalmente nos damos conta da finitude da nossa existência, por exemplo, em experiências de doença, incapacitação ou de morte inevitável, isso também transforma a nossa relação conosco mesmos e com o mundo, assim como os nossos valores. (JOAS, 2012. p.105)

No campo jornalístico, Rocha e Santos (2013) dizem que o tema sempre foi norteador de pautas, especialmente no chamado jornalismo sensacionalista, ao lado de temas como celebridades, ciúme e sexo. É recorrente identificarmos nas capas dos mais variados jornais (online ou impressos) uma morte estampada. Os autores também nos falam da publicidade que o morrer ganha com a expansão dos meios de comunicação

[...] o tema da morte nunca sai de cena: a morte está presente cotidianamente nos jornais, retratada de forma espetacular, ficcionalizada, como uma novela ou filme que nunca tem fim. É com a eclosão dos meios de comunicação, a partir do século XX, que a morte torna-se pública, entra para dentro das casas, e os gestos rituais 


\section{Observatório}

ISSN n² 2447-4266

Vol. 4, n. 1, Janeiro-Março. 2018

DOI: http://dx.doi.org/10.20873/uft.2447-4266.2018v4n1p599

daqueles tipificados como importantes pelas mídias são intensificados e espetacularizados. (ROCHA; SANTOS, 2013, p.2)

O que pode ser observado no campo midiático é uma seleção das mortes que ganham visibilidade. Rondelli e Herschmann (2000) discutem a questão ao tratar do aspecto biográfico dessas narrativas midiáticas de mortes de famosos. Vem à tona a diferença de tratamento entre anônimos e famosos quando as mortes do primeiro grupo ficam relegadas aos espaços consagrados para o morrer (hospitais, asilos, clínicas, cemitérios) e, em oposição, "as sociedades contemporâneas têm, cada vez mais, reconduzido a morte de alguns notórios eleitos ao 'mundo dos vivos' através de sua encenação mediática. [...] De certa forma, a morte recupera seu caráter público, condição que ela já teve na Idade Média [...]." (RONDELLI; HERSCHMANN, 2000, p.204205).

É um duplo movimento, uma prática social que depende da fama do morto. Um exemplo empírico do descompasso foi observado por Simões (2015) na cobertura das mortes de Eduardo Campos, então candidato à Presidência da República e dos outros seis tripulantes da aeronave. A pesquisadora observa como a tragédia do avião estabelece um "luto [...] vivido de forma pública, e o funeral acompanhado por milhares de pessoas em Recife." (SIMÕES, 2015, p.15). As mortes dos anônimos são noticiadas, mas não com a mesma intensidade e nem acompanhadas com tanta avidez pelos vivos, como a de Campos.

\section{Análise}

As categorias de análise captadas na obra de Quéré e mobilizadas por diferentes pesquisadores (FRANÇA, 2011; LANA, 2010; SIMÕES, 2012; 


\section{Observatório}

ISSN n² 2447-4266

Vol. 4, n. 1, Janeiro-Março. 2018

DOI: http://dx.doi.org/10.20873/uft.2447-4266.2018v4n1p599

SARMENTO, MENDONÇA, 2007; SILVA, 2011) são operacionalizadas no intuito de compreender o que Quéré nomeia de individuação do acontecimento. Neste artigo, procuramos apreender o acontecimento em foco através de três eixos: a descrição, a narração/temporalização e o contexto pragmático, segundo a metodologia utilizada por Simões (2012). Com isso, buscamos compreender o poder hermenêutico dessa ocorrência, ou seja, o que ela revela sobre o contexto social mais amplo em que se inscreve.

Trabalhamos com uma amostra do material impresso produzido por dois dos jornais de maior circulação no país, O Globo e Folha de S. Paulo, durante os meses de junho, julho e agosto de 2010 (período inicial do caso). A coleta foi realizada em fevereiro de 2015, através dos mecanismos de busca dos acervos dos jornais usando as palavras: "eliza samúdio". O recorte foi necessário diante de um volume de material extenso (mais de 1000 matérias combinando os dois jornais) e considerando o desenrolar de mais de quatro anos do caso.

Assim, o corpus utilizado é composto de 200 unidades de análise em ambos os jornais, distribuídas em notas, chamadas, artigos e reportagens, durante o período de 27 de junho de 2010 (primeiro resultado encontrado em ambos os arquivos) até o dia 27 de agosto de 2010. Esse foi o espaço temporal no qual foi delineado o caso (desaparecimento de Eliza, depoimento de Bruno e investigação), com o surgimento dos personagens centrais e indiciamento no inquérito policial dos envolvidos no acontecimento.

A seguir, apresentamos os principais resultados da análise realizada a partir dos três eixos apontados anteriormente (a descrição, a narração/temporalização e o contexto pragmático), no intuito de apreender o seu poder hermenêutico, ou seja, sua capacidade de revelar problemas e sentidos latentes na sociedade - o que será discutido na seção final do texto. 


\section{Obevisto}

ISSN n² 2447-4266

Vol. 4, n. 1, Janeiro-Março. 2018

DOI: http://dx.doi.org/10.20873/uft.2447-4266.2018v4n1p599

\section{Descrição}

O momento da descrição do acontecimento "é o processo através do qual o acontecimento é categorizado e inscrito em certos 'quadros' (GOFFMAN, 1991), ou seja, como ele é definido, enquadrado." (SILVA, 2014). Podemos dizer que o acontecimento é nomeado nesta fase da análise.

Eliza Samúdio é dada como desaparecida por volta do dia 26 de junho de 2010. Neste momento, ela é descrita como ex-namorada de Bruno Fernandes (goleiro do Flamengo à época), estudante e jovem desaparecida. É levantada uma suspeita de assassinato ${ }^{7}$ pela delegada responsável pelo caso, Alessandra Wilke, logo refutada pela coordenação policial do mesmo. O delegado Edson Moreira, superior de Wilke, diz que "enquanto não houver corpo, trata-se só de um desaparecimento"8. O caso desperta o interesse do público em virtude do envolvimento do goleiro, que nega qualquer relação com o assunto. A relação, entretanto, é estabelecida quando o filho de Eliza e Bruno é encontrado com a esposa do jogador, Dayane, no fim de junho, e a polícia militar recebe denúncias anônimas sobre espancamento de Eliza por Bruno e dois amigos, no sítio do goleiro. O caso se desenrola com a incorporação de vários outros atores e a tentativa de preencher as lacunas temporais que configuram a intriga do acontecimento. Com o desenrolar da investigação, ocorre o indiciamento do goleiro e mais sete pessoas responsabilizadas por seis crimes (homicídio, sequestro e cárcere privado, ocultação de cadáver, formação de quadrilha e corrupção de menores), além de

\footnotetext{
${ }^{7}$ Goleiro terá que depor sobre jovem sumida/O Globo/27.06.2010

${ }^{8}$ Sítio de goleiro é vasculhado pela polícia/Folha/29.06.2010/Cotidiano
} 


\section{Obsisto}

ISSN n² 2447-4266

Vol. 4, n. 1, Janeiro-Março. 2018

DOI: http://dx.doi.org/10.20873/uft.2447-4266.2018v4n1p599

Marcos Aparecidos do Santos, indiciado por crimes diferentes (homicídio triplamente qualificado, formação de quadrilha e ocultação de cadáver) ${ }^{9}$.

O enquadramento geral utilizado, no início da cobertura jornalística (final do mês de junho de 2010), é o desaparecimento de uma ex-namorada do goleiro do Flamengo, envolvido na história. Com o passar dos dias, os depoimentos e o avançar da investigação, "crime de homicídio" começa a ser um quadro mobilizado. Observamos a disputa pelos sentidos desse enquadramento pela falta de corpo, materialidade substantiva, prova irrefutável da morte. O mundo jurídico, com os jargões e os meandros da lei aparecem em vários momentos, inclusive nos comentários de leitores, alegando a impossibilidade de julgar um crime pela inexistência de um cadáver.

O acontecimento passa a ser identificado pela mídia dessas duas maneiras: desaparecimento e homicídio, às vezes ao mesmo tempo. A defesa do goleiro chega a dizer "a jovem está viva e, por vingança, não quer aparecer para mantê-lo preso." ${ }^{10}$. O advogado de Bruno, Ércio Quaresma, expõe um argumento que é mobilizado algumas vezes ao descrever o acontecimento: "Enquanto eu não verificar um atestado de óbito, enquanto não cotejar um exame de necropsia, essa moça está viva"11, logo, se ela está viva, só está desaparecida e não se pode falar em homicídio.

Eliza é descrita como "ex-amante", "ex-namorada", "ex de Bruno", em grande parte das matérias. Ou seja, a associação primeira sempre é feita com o jogador, o famoso. Eliza, até então, é anônima. A descrição mais usual de Bruno Fernandes no material coletado é "goleiro do Flamengo". Ele (o homem famoso) é identificado, assim, por sua profissão; ela (a mulher anônima), apenas

\footnotetext{
${ }^{9}$ Caso Bruno: promotor denuncia nove/O Globo/05.08.2010

${ }^{10}$ Defesa de Bruno diz que Eliza está viva/FOLHA/21.07.2010/Cotidiano

${ }^{11}$ Idem.
} 


\section{Observatório}

ISSN n² 2447-4266

Vol. 4, n. 1, Janeiro-Março. 2018

DOI: http://dx.doi.org/10.20873/uft.2447-4266.2018v4n1p599

por seu relacionamento amoroso com o atleta - evidenciando aqui uma das faces da assimetria que marca as relações de gênero em nossa sociedade.

Bruno Fernandes depõe a favor de Adriano quando este se envolve em uma agressão à noiva Joana Machado dizendo:

Qual de vocês (jornalistas) que é casado que nunca brigou com a mulher? Que não discutiu, que não até saiu na mão com a mulher, né cara? Não tem jeito. Em briga de marido e mulher, ninguém mete a colher, xará. Então eu acho que isso é problema pessoal do cara. ${ }^{12}$

Este depoimento volta às páginas dos jornais durante o acontecimento relacionado à Eliza ${ }^{13}$, explorando os envolvimentos dos jogadores de futebol com o crime, com a polícia. Na articulação da reportagem de O Globo, esse depoimento é usado para descrever o jogador como alguém que "parece ter personalidade forte" e que causa polêmicas, que inclusive precisou pedir desculpas às mulheres que ficaram revoltadas com a declaração. Não há menção às acusações anteriores de Eliza.

Isso ressalta a utilização de outro enquadramento: o de violência de gênero. Quando um dos primos de Bruno conta o motivo pelo qual Eliza teria sido morta ("ela estava dando muita aporrinhação"14), o discurso midiático endossa essa visão ao apontar como causa do acontecido à Eliza a "insistência para que Bruno reconhecesse a criança e the pagasse uma pensão"15. O discurso de culpabilização da vítima é recorrente e aponta para a lacuna, neste

\footnotetext{
${ }^{12}$ Disponível em: <http://esporte.ig.com.br/futebol/2010/03/07/bruno+se+dispoe +ate+a+voltar+a+favela+para + apoiar+adriano+9419949.html> . Acesso em 10/02/2015.

${ }_{13}^{13}$ Polêmica ao defender Adriano/O Globo/28.06.2010

14 Eliza ficou dois dias na casa de Bruno no Rio antes de ir a MG, diz garoto/FOLHA/13.07.2010/cotidiano

${ }_{15}$ Presença de Bruno na cena do crime é principal dúvida/FOLHA/18.07.2010/Cotidiano
} 


\section{Observatório}

ISSN n² 2447-4266

Vol. 4, n. 1, Janeiro-Março. 2018

DOI: http://dx.doi.org/10.20873/uft.2447-4266.2018v4n1p599

enquadramento do gênero, de discursos midiáticos menos dotados de preconceitos.

Em outros crimes de semelhante fundamentação, que "não se referiam explicitamente à relação e papéis de gênero, aos valores e normas que estão sendo defendidos e/ou infringidos nestes casos, à especificidade da violência de gênero", como nos diz França (2011) sobre o caso Eloá, também é possível notar o quanto essas especificidades são deixadas de lado nas descrições do acontecimento. O caso de Ângela Diniz, por exemplo, ou o "crime da mansão da Pampulha" referindo-se ao assassinato de Eloísa Ballesteros, são identificados como crimes, mas muito menos como crimes de gênero.

A violência contra a mulher nos casos acima citados aparece em segundo plano, demora a ser nomeada pela cobertura midiática, o que pode nos sugerir um modo de ver e fazer jornalístico menos preocupado com as questões políticas de gênero (LANA, 2010). Doca Street, parceiro de Ângela Diniz, atira quatro vezes na face e na nuca da mulher. Ainda assim, consegue apoio da opinião pública em um primeiro momento e uma condenação curta. O acontecimento é enquadrado como "crime por amor" (LANA, 2010, p.70), passional, para proteger a honra. Já no caso Eloá, o crime é enquadrado como sequestro inicialmente $\mathrm{e}$, somente com o desfecho trágico, vem à tona a violência de gênero. Por fim, Marcio Stancioli é condenado por matar sua esposa, Eloisa Ballesteros, com cinco tiros. A pena, entretanto, é homicídio culposo, sem intenção de matar, e o juiz concede suspensão condicional por bons antecedentes e pelo fato de ele ser réu primário. $O$ caso também é enquadrado como crime passional que, segundo Corrêa e Chrystus (2012, p.161), "muitas vezes substitui a palavra 'assassinato', suavizando, de certa 


\section{Observatónio}

ISSN n² 2447-4266

Vol. 4, n. 1, Janeiro-Março. 2018

DOI: http://dx.doi.org/10.20873/uft.2447-4266.2018v4n1p599

forma, o delito cometido por aquelas pessoas - homens, em sua grande maioria".

Quando acusações antigas de Eliza vêm à tona - ela disse ter sido obrigada a ingerir abortivos e ameaçada por Bruno ${ }^{16}$ em outubro de 2009 - os discursos midiáticos reportam a ocorrência, e surge a questão da interpretação da Lei Maria da Penha. Esta não fora aplicada ao caso pelo fato de a juíza em questão não enxergar o envolvimento de Eliza o suficiente para ser respaldada pela justiça.

Após o depoimento de um primo de Bruno Fernandes, menor de idade àquela época com 17 anos, outro personagem entra na trama, o ex-policial Marcos Aparecido dos Santos. Conhecido também como Bola, Neném e Marquinhos Paulista, Marcos é descrito como "especialista em matar"17. A partir desse momento, o crime ganha enquadramentos mais incisivos de barbárie, horror, crueldade e violência.

Através da descrição do acontecimento, pudemos analisar alguns enquadramentos possíveis para a morte de Eliza Samúdio. É importante lembrar que "Estes quadros de sentido, estes princípios de inteligibilidade são claramente sociais e históricos; exatamente porque organizam a vida social [...] eles não são (não podem ser) individuais, mas compartilhados coletivamente" (FRANÇA, 2011, p.68-69). E justamente por serem compartilhados, nos ajudam a pensar em como o acontecimento afeta a sociedade, expõe sentidos e diz sobre as próprias pessoas. Nas ruas, no cotidiano e na cobertura midiática, os enquadramentos sobre o caso falam sobre nós.

\footnotetext{
${ }^{16}$ IML retém há 8 meses resultado de exame que detecta abortivo/FOLHA/30.06.2010/Cotidiano

${ }^{17}$ Ex-policial acusado de matar Eliza é preso/FOLHA/09.07.2010/Cotidiano
} 


\section{Observatório}

ISSN n² 2447-4266

Vol. 4, n. 1, Janeiro-Março. 2018

DOI: http://dx.doi.org/10.20873/uft.2447-4266.2018v4n1p599

\section{Narração}

Nesse segundo passo da análise, evidenciamos os personagens centrais na construção do acontecimento e as marcações temporais que surgem a partir dele. Eliza Samúdio, uma jovem de 25 anos, apontada como ex-namorada e examante de Bruno, é a vítima do acontecido. Bruno Fernandes, goleiro do Flamengo, mandante do crime, é a outra ponta da intriga do acontecimento. Entre os dois, vários diferentes personagens surgem e têm ligação.

Essas pessoas constroem uma trama e são envolvidas no acontecimento, adicionando informações que nos ajudam na narração do mesmo, pois trazem o passado e o futuro, a perspectiva temporal: "ao desorganizar o presente, o acontecimento instala" (QUÉRÉ, 2012, p.47). Quéré nos diz que essa "temporalidade estendida convoca um passado com o qual ele possa estabelecer ligações, anuncia futuros possíveis" (idem, 2012, p.47).

As biografias de Bruno e Eliza são convocadas pelo acontecimento na tentativa de explicar o que aconteceu. Buscar as respostas no passado de ambos, nas experiências sofridas, além de situá-los para o leitor. "Assim como Eliza Samúdio, o goleiro Bruno não teve contato com a mãe na infância"18, foi criado pela avó depois do abandono da mãe. Outro aspecto da vida pregressa de Bruno é sua mudança de comportamento, segundo amigos e conhecidos antigos, provocada pela fama súbita decorrente de sua carreira como futebolista.

No passado de Eliza, o abandono, ainda criança, é mobilizado pelo pai para justificar porque sua filha jamais deixaria seu bebê, "uma vez que seria traumatizada por ter sido ela mesma abandonada pela mãe quando criança"19,

\footnotetext{
${ }^{18}$ Deixado pela mãe, jogador foi criado pela avó/FOLHA/06.07.2010/Cotidiano

${ }^{19}$ Sítio de goleiro é vasculhado pela polícia/FOLHA/29.06.2010
} 


\section{Observatório}

ISSN n² 2447-4266

Vol. 4, n. 1, Janeiro-Março. 2018

DOI: http://dx.doi.org/10.20873/uft.2447-4266.2018v4n1p599

hipótese levantada no começo das investigações. A carreira de atriz pornográfica, seu relacionamento com outros jogadores de futebol e sua relativa "fama" entre os jogadores como "maria chuteira" são elementos biográficos retomados com o objetivo de explicar a aproximação com Bruno e a posterior morte.

O acontecimento desloca a posição de anônima de Eliza, no passado, para a de personalidade conhecida naquele momento, ao relacioná-la com um famoso do futebol, o goleiro Bruno. Isso também acontece com o delegado responsável pelas investigações, Edson Moreira da Silva, apontado como uma "estrela" no caso. A reportagem da Folha de S. Paulo diz que "Moreira chegou a dar duas entrevistas coletivas por dia sobre o caso Eliza, fora conversas rápidas com os repórteres e participações ao vivo em telejornais e programas policiais vespertinos." ${ }^{20}$ A possibilidade de ser famoso/conhecido é aberta a Moreira da Silva com o acontecimento, assim como para Eliza.

Todo o processo desencadeia, da mesma forma, um horizonte de possibilidades para Bruno. Ele lamenta perder a oportunidade de representar o Brasil na Copa do Mundo de 2014 e ver sua carreira interrompida naquele momento: "a diretoria rubro-negra avalia que não terá mais como recuperar o investimento financeiro investido em Bruno, e quer se precaver para rescindir o contrato por justa causa. ${ }^{21}$. Os patrocínios também ficaram comprometidos, o momento é de "grande exposição negativa" segundo a reportagem, tanto para Bruno, quanto para o Flamengo ${ }^{22}$.

A narração do caso mostra também uma midiatização do acontecido que acaba por inseri-lo na memória coletiva. O que Bruck (2010, p.29) chama de

\footnotetext{
${ }^{20}$ Delegado é investigado em três inquéritos em MG/FOLHA/14.07.2010

${ }^{21}$ Fla suspende contrato/O Globo/08.07.2010/p.15

${ }^{22}$ Fla suspende contrato/O Globo/08.07.2010/p.15
} 


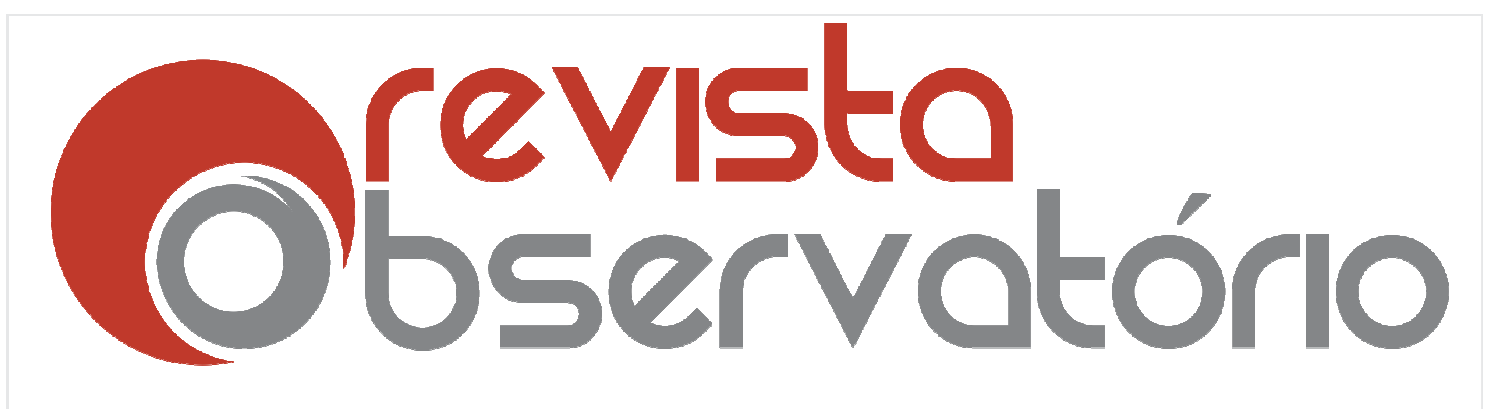

ISSN n² 2447-4266

Vol. 4, n. 1, Janeiro-Março. 2018

DOI: http://dx.doi.org/10.20873/uft.2447-4266.2018v4n1p599

"canal multitemporal" e "enquadramento do acontecido", a memória coletiva é construída, entre outros elementos, pelos relatos sobre o caso, pelas peças de biografia de cada um dos envolvidos, pelo material midiático produzido, pelas experiências individuais e pela afetação do ocorrido em cada um. A memória é multitemporal por sobrepor o passado do acontecimento e o presente que estava se desenrolando ao vivo (e continua até hoje), e projetar um futuro. No caso de Eliza, a morte. Sem o corpo, sem rituais funerários, enterro, sem "morte consumada" (VOVELLE, 1987), Eliza morre na mídia.

\section{Pano de fundo pragmático}

No terceiro eixo de individuação do acontecimento, o pano de fundo pragmático, retomamos o contexto em que o caso se inscreve. São falas, declarações e discursos sobre o acontecido, além de valores e práticas, ações e reações, que podem revelar mais uma camada de sentidos para a análise.

O início do acontecimento apresenta os companheiros de time de Bruno demonstrando empatia, dizendo passar por um momento doloroso. Léo Moura, então jogador do Flamengo, se solidariza com o goleiro: "É triste ver um companheiro nessa situação. Me doi demais." 23 . Ao mesmo tempo, a carta de um leitor questiona o apoio que Bruno recebe:

[...] tempos de barbárie. O caso Bruno é horripilante, com requinte de crueldade e covardia. Não bastasse tanta sordidez, temos que assistir ao sr. Leo Moura lamentar [...] a perda que o Flamengo terá com a saída do goleiro Bruno, sem demonstrar perplexidade de estar jogando ao lado de um psicopata ou, pelo menos externar seu repúdio ao ato insano de seu colega de clube. Total inversão de valores. [...]O Flamengo precisa acionar sua assessoria de imprensa para evitar essa exposição, que denigre a imagem do time mais

\footnotetext{
${ }^{23}$ Fla tenta Ronaldinho/O Globo/08.07.2010/p.8 - Esportes.
} 


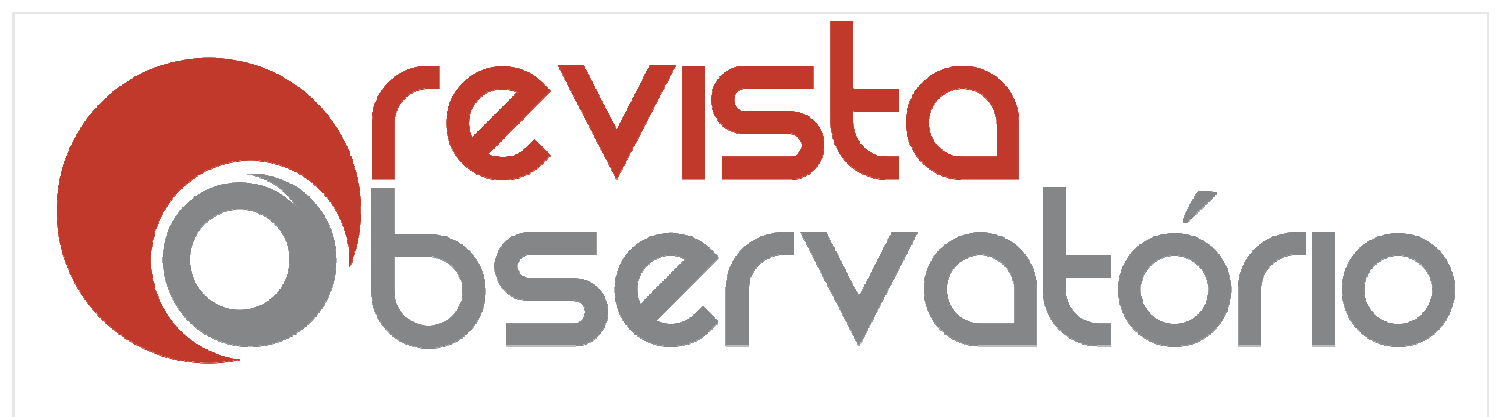

ISSN n² 2447-4266

Vol. 4, n. 1, Janeiro-Março. 2018

DOI: http://dx.doi.org/10.20873/uft.2447-4266.2018v4n1p599

querido do brasil. E que o clube inclua um teste de sanidade mental antes de assinar contrato com esses psicóticos. ${ }^{24}$

O comentário do leitor expõe não só sua revolta com o apoio que o jogador recebe, mas também a recorrência do envolvimento dos jogadores de futebol com atitudes reprováveis. Wagner Love e Adriano são lembrados como envolvidos em investigações policiais, e isso contribui para uma visão do futebol em que há "inversão de valores". Sob o subtítulo "Patrocinem atletas e não delinquentes", Elio Gaspari diz:

Se em março passado o Flamengo e os patrocinadores de Adriano e Vagner Love tivessem exemplado os dois atletas por manterem relações perigosas com a bandidagem do Rio de Janeiro, talvez o goleiro Bruno tivesse percebido que jogador de futebol não tem carta de impunidade. ${ }^{25}$

O mundo do futebol é lembrado para falar de como a "fama corrompe", do sucesso fugaz dos jogadores e, de alguma forma, servir de justificativa para os desvios cometidos pelos atletas ${ }^{26}$. Esse movimento de justificativa dos crimes dos jogadores gera um sentimento de impunidade por parte da população, que clama "da justiça uma punição exemplar, pois as coisas estão fora do controle"27, e indica o lugar dos ídolos e do próprio futebol. O julgamento moral dos jogadores é feito ao longo de vários comentários, revelando uma esperança de que a conduta do atleta seja levada em consideração pelos times e patrocinadores.

Ainda no âmbito do futebol, a fama também é elemento convocado pela população. $O$ fato de os jogadores serem bem remunerados, saírem de uma

\footnotetext{
${ }_{24}^{24}$ Dos leitores/O Globo/10.07.2010

${ }^{25}$ GASPARI, Elio./FOLHA/11.07/2010

${ }_{27}^{26}$ Sucesso de Bruno foi "virada" para amigos/FOLHA/11.07.2010/Cotidiano

27 Dos leitores/O globo/30.06/2010
} 


\section{Observatório}

ISSN n² 2447-4266

Vol. 4, n. 1, Janeiro-Março. 2018

DOI: http://dx.doi.org/10.20873/uft.2447-4266.2018v4n1p599

condição de anonimato para outra de celebridades, é o que, segundo um leitor, faz meninas "se aproximar de jogadores renomados, algumas simplesmente visando a desfrutar momentos de fama, outras - infelizmente a maioria - em busca de ganhos financeiros". Percebe-se um julgamento moral a Eliza, considerada "maria-chuteira", ao se envolver com Bruno, e às garotas que mantêm relações com jogadores de futebol de maneira geral.

A fama de Bruno também é descrita como a catalisadora de seu comportamento agressivo e da mudança da personalidade do jogador, o que nos sugere uma interpretação do sucesso como algo que pode influenciar psicologicamente.

Em oposição à imagem de "maria-chuteira", aparece uma Eliza mãe. Segundo o investigador Marco Fonseca, "Infelizmente, tudo indica que ela esteja morta, pois mãe não abandona filho de quatro meses. Já estamos em busca do corpo" ${ }^{28}$. Essa fala de Marco faz emergir o valor da maternidade, reforçado pela família e por amigas da moça, mostrando o quanto nossa sociedade ainda associa a mulher a um papel idealizado de mãe, com todas as características que the são normalmente atribuídas: amor incondicional pelos filhos, responsabilidade e cuidado.

Entre as reações desencadeadas pelo acontecimento estão a cobrança à polícia e ao Estado por uma investigação eficaz para os outros desaparecidos do país. Aqui, é reforçado o quanto a fama dos envolvidos e a exposição midiática contribuem para chamar atenção das autoridades e "resolver um problema":

Tomara que a enorme, dedicada e competente força tarefa da Polícia Civil de Minas Gerais que está empenhada em esclarecer o midiático caso do desaparecimento de Eliza Samúdio, ex-namorada do goleiro

${ }^{28}$ Goleiro do Fla vira alvo da polícia/FOLHA/27.06.2010 


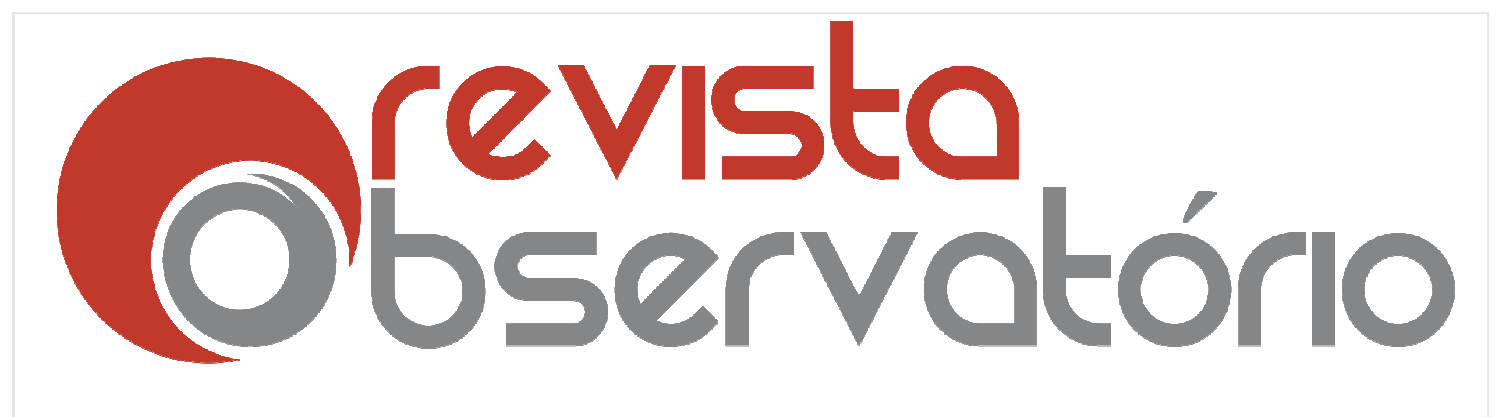

ISSN n² 2447-4266

Vol. 4, n. 1, Janeiro-Março. 2018

DOI: http://dx.doi.org/10.20873/uft.2447-4266.2018v4n1p599

Bruno, do Flamengo, seja doravante também utilizada para esclarecer os outros 1.022 casos de cidadãos atualmente desaparecidos no Estado de Minas (alguns há décadas)[...]. As milhares de famílias que choram angustiadamente a ausência dos seus entes queridos agradecerão. ${ }^{29}$

Assim como citado na descrição do acontecimento, a violência de gênero perpassa o discurso midiático. Contudo, nas declarações, observamos a população questionando não só a demora da polícia do Rio de Janeiro em liberar o laudo toxicológico que comprovaria uma tentativa de aborto denunciado por Eliza, como a não aplicação da Lei Maria da Penha:

No acontecimento Eliza, [...] nota-se a tematização do escopo da lei e da viabilidade de sua aplicação a situações singulares. $O$ fato de uma juíza ter definido que a lei não se adequaria a uma denúncia específica de violência levanta todo um debate sobre a definição do bem-viver e dos tipos de laços afetivos a serem protegidos. (SARMENTO; MENDONÇA, 2013, p.23).

O caso expõe um problema público que acomete a sociedade e que recebe pouca atenção: o da violência sistemática e invisível às mulheres. Segundo o "Mapa da Violência 2010, feito pelo Instituto Sangari" ${ }^{\text {"30 }}$, cada duas horas uma mulher morreu entre 1997 e 2007. Rebecca Tavares, em um texto para a Folha de S. Paulo, articula esse dado a fim de chamar a atenção:

[...] o que revela clara e urgente necessidade para que os esforços do Estado brasileiro, aos quais nos somamos, tragam melhores estratégias e resultados de prevenção. Conclamamos a sociedade brasileira para que o sentimento de estarrecimento desses casos seja revertido em ações práticas, individuais e coletivas de denúncia e apoio às vítimas de violência. [...] incorporemos a ideia de que a violência contra as mulheres é inaceitável, indesculpável e intolerável ${ }^{31}$

\footnotetext{
${ }^{29}$ Dos leitores/O GLOBO/30.06/2010

30 Tendências e debates/FOLHA/16.07.2010

${ }^{31}$ Tendências e debates/FOLHA/16.07.2010
} 


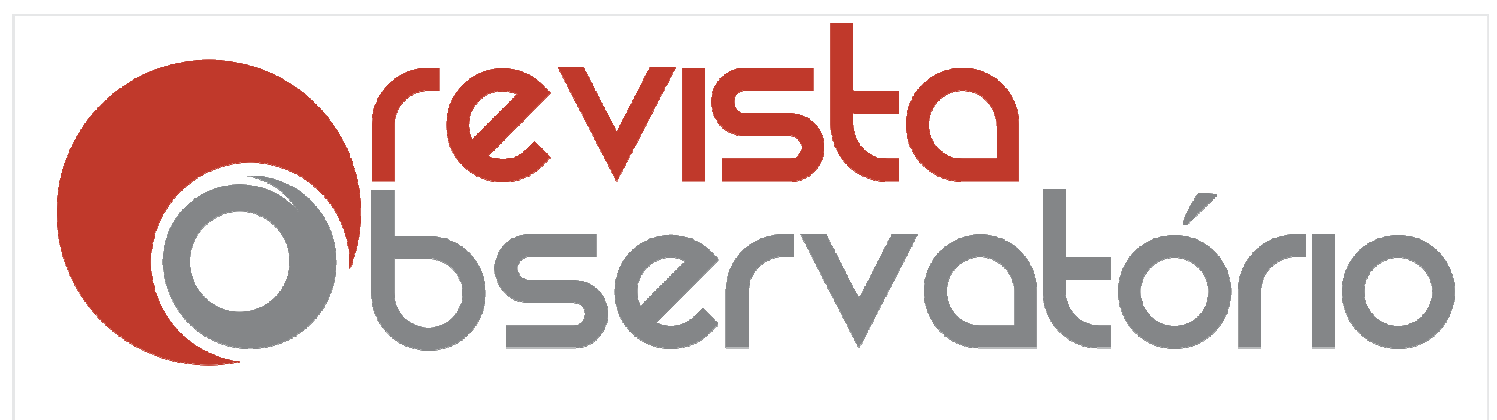

O acontecimento também mobiliza para discutir a pena aos autores de crimes de gênero e como a impunidade nesses casos é recorrente. Ruy Castro aponta a pressa em julgar da sociedade e apontar culpados, mas retoma o assassinato de Sandra Gomide e seu assassino confesso, em liberdade. Assim como o comentário da leitora:

Será que podem ter alguma esperança de justiça os familiares de Mércia Nakashima e Eliza Samúdio, quando neste mês completam-se dez anos do assassinato da jornalista Sandra Gomide, e o réu confesso Antonio Pimenta Neves segue em liberdade? ${ }^{32}$

\section{Conclusão}

O objetivo deste texto foi analisar a morte de Eliza Samúdio pelo viés do acontecimento. Através da discussão em torno do processo de individuação, pudemos observar elementos descritivos, narrativos e constitutivos do pano de fundo pragmático do caso Eliza. Foi possível observar uma descrição do acontecimento como desaparecimento e/ou assassinato e os enquadramentos utilizados na cobertura jornalística ao descrever Eliza, Bruno e o que estava acontecendo no momento. No segundo eixo analítico, a narração apresenta a temporalidade do processo, na tentativa de captar o passado que culmina no acontecimento e os futuros descortinados, além de alguns elementos biográficos recuperados dos dois que ajudam a construir um cenário para 0 acontecimento. Por fim, o contexto de fundo traz as falas, as ações e as reações provocadas pelo acontecimento, desde a revolta com o ocorrido e com a violência contra as mulheres, o julgamento de garotas que se relacionam com jogadores de futebol até discussões sobre as consequências da fama.

\footnotetext{
${ }^{32}$ Painel do leitor/FOLHA/13.08.2010
} 


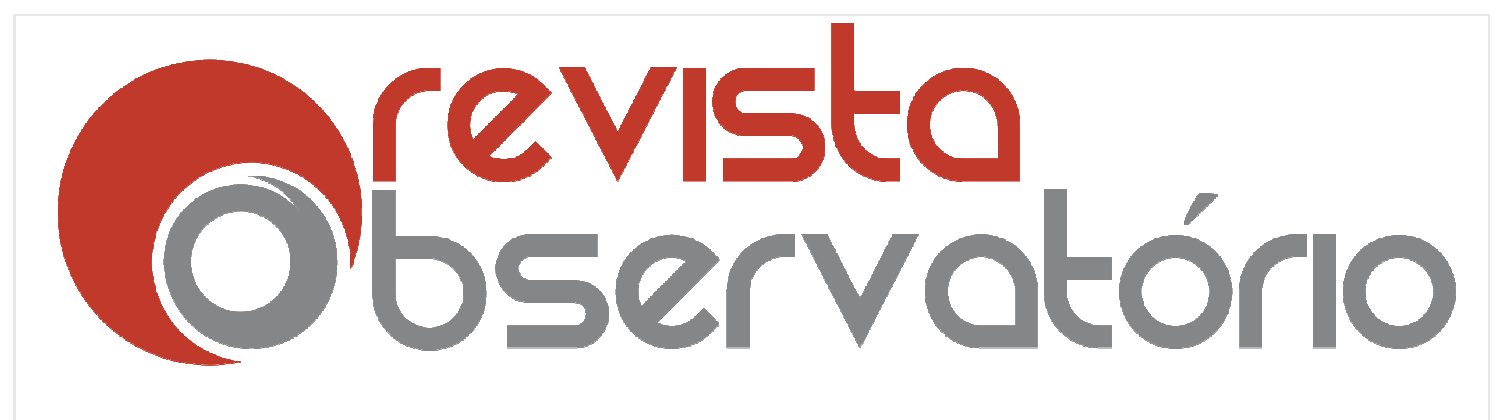

ISSN n² 2447-4266

Vol. 4, n. 1, Janeiro-Março. 2018

DOI: http://dx.doi.org/10.20873/uft.2447-4266.2018v4n1p599

A partir dessa análise, buscamos compreender o poder hermenêutico do mesmo para concluir a presente reflexão. Segundo Sarmento e Mendonça (2013, p.4)

o poder hermenêutico dos eventos, [...] se traduz em sua capacidade de revelação (Arendt, 1993; Quéré, 2005; França, 2012). Acontecimentos criam as condições de sua compreensão ao jogar luz sobre o mundo, permitindo que ele seja reinterpretado e reconcebido.

O acontecimento que envolveu Eliza e Bruno lança luz, sobretudo, sobre quatro questões. Em primeiro lugar, ele revela o poder do futebol e a influência desse esporte no cotidiano da nossa sociedade. O caso é inicialmente atrelado ao goleiro do Flamengo, o que garante visibilidade. A celebrização dos jogadores contribui para tornar notícia não só seus feitos em campo, mas concomitantemente suas vidas privadas.

Em segundo lugar, a oposição fama $x$ anonimato também é revelada com o acontecimento ao opor anônimos, como inicialmente Eliza e todos os outros personagens do crime, e o famoso Bruno. Como em outros casos envolvendo os dois lados, por exemplo, a morte do presidenciável Eduardo Campos, há assimetrias na cobertura midiática, o que nos diz do conteúdo produzido pelos media e consumido pela sociedade.

Em terceiro lugar, o acontecimento ilumina a realidade da morte e o modo como a mídia e a sociedade lidam com ela. Apesar de a morte de Eliza não ser declarada oficialmente pela falta de um corpo, a sua morte simbólica acontece na mídia e choca, pelos detalhes com que é descrita e pela banalidade das justificativas. Essa realidade da morte provoca um deslocamento da ordem natural que é próprio da constituição de acontecimentos. 


\section{Observatório}

ISSN n² 2447-4266

Vol. 4, n. 1, Janeiro-Março. 2018

DOI: http://dx.doi.org/10.20873/uft.2447-4266.2018v4n1p599

Em quarto e último lugar, o grande problema público revelado por esse acontecimento diz respeito à violência de gênero. Explorando principalmente os dilemas legais da aplicação da lei Maria da Penha e o quão invisibilizado esse tipo de violência ainda é, a partir de um crime que choca e espanta, vem à tona a cobrança do Estado em proteger e garantir segurança a essas mulheres.

Ao lançar luz sobre esses quatro eixos, a morte de Eliza afeta a sociedade e convoca seus membros a se posicionar. Se a morte nos afeta em função da sacralidade (JOAS, 2012) que nos constitui como pessoas, ela também nos toca por aquilo que ela diz de nós e de nossa sociedade. E, se o confronto com a finitude de nossa existência pode transformar "a nossa relação conosco mesmos e com o mundo, assim como os nossos valores" (JOAS, 2012, p.105), mortes como a de Eliza podem impulsionar os sujeitos a repensarem o mundo em que vivem e seu quadro de valores. É dessa forma que um acontecimento, ao fazer falar (FRANÇA, 2012) e ao fazer pensar, pode transformar o contexto social em que se inscreve e que ajuda a construir.

\section{Referências}

BRAUDY, Leo. The Frenzy of Renown: Fame and Its History. New York: Vintage Books, 1997.

BRUCK, Mozahir Salomão. Biografias e literatura: entre a ilusão biográfica e a crença na reposição do real. Belo Horizonte: Veredas \& Cenários, 2010.

CORRÊA, Laura G.; CHRYSTUS, Mirian. No adro da igreja: o assassinato de mulheres e a potencialização de acontecimentos entrelaçados. In: FRANÇA, Vera; OLIVEIRA, Luciana de (Organizadoras). Acontecimento: reverberações. Belo Horizonte: Autêntica, 2012. P. 157 - 169.

DEWEY, John. Arte como experiência. São Paulo: Martins Fontes, 2010. 


\section{Obevisto}

ISSN n² 2447-4266

Vol. 4, n. 1, Janeiro-Março. 2018

DOI: http://dx.doi.org/10.20873/uft.2447-4266.2018v4n1p599

FRANÇA, Vera. R. V. O crime e o trabalho de individuação do acontecimento no espaço midiático. Caleidoscópio-Revista de Comunicação e Cultura, n. 10, 2011.

FRANÇA, Vera. O acontecimento para além do acontecimento: uma ferramenta heurística. In: FRANÇA, Vera. OLIVEIRA, Luciana de (Organizadoras). Acontecimento: reverberações. Belo Horizonte: Autêntica, 2012.

FRANÇA, Vera; OLIVEIRA, Luciana de (Organizadoras). Acontecimento: reverberações. Belo Horizonte: Autêntica, 2012

HERSCHMANN, Micael; PEREIRA, Carlos Alberto M. Mídia, memória e celebridades. Editora E-papers, 2003.

JOAS, Hans. A sacralidade da pessoa: nova genealogia dos direitos humanos. São Paulo: UNESP, 2012

LANA, C. Acontecimento midiático e ressonâncias pragmáticas: a produção de sentido em torno de crimes passionais. 2010. Monografia (Graduação em Comunicação Social) - Faculdade de Filosofia e Ciências Humanas, Universidade Federal de Minas Gerais, Belo Horizonte, 2010.

LEAL, Bruno Souza. et al. Agendamento, enquadramento e noticiabilidade. In: BENETTI, Marcia; FONSECA, Virginia P. S. (org.). Jornalismo e acontecimento: mapeamentos críticos. Florianópolis: Insular, 2010. P.187-219.

LIPOVETSKY, Gilles; SERROY, Jean. A cultura-mundo: resposta a uma sociedade desorientada. São Paulo: Companhia das Letras, 2011.

MENDONÇA, R. F. Movimentos Sociais como acontecimentos: linguagem e espaço público. Lua Nova, Revista de cultura e política, São Paulo, n. 72, p. 115$142,2007$.

PRIMO, Alex. De narcisismo, celebridades, celetoides e subcelebridades: o caso Tessália e sua personagem Twittess. Comunicação Mídia e Consumo, v. 7, n. 20, p. 159-189, 2011.

QUÉRÉ, Louis. Entre o facto e sentido: a dualidade do acontecimento. In: TRAJECTOS, Revista de Comunicação, Cultura e Educação, Lisboa, Instituto 


\section{Observatório}

ISSN n² 2447-4266

Vol. 4, n. 1, Janeiro-Março. 2018

DOI: http://dx.doi.org/10.20873/uft.2447-4266.2018v4n1p599

Superior de Ciências do Trabalho e da Empresa - Departamento de Sociologia Seção de Comunicação, Cultura e Educação, n.6, 2005. P. 59-75.

QUÉRÉ, L. A dupla vida do acontecimento: por um realismo pragmatista. In: FRANCA, V. R. V.; OLIVEIRA, L. (Org.). Acontecimento: reverberações. Belo Horizonte: Autêntica, 2012. p. 21-38.

REDMOND, S. Intimate fame everywhere. In: HOLMES, S.; REDOND, S. (eds). Framing celebrity: new directions in celebrity culture. New York: Rutledge, 2006, p. 27-43.

ROCHA, Paula R. S.; SANTOS, Goiamérico F. C. dos. A morte como espetáculo midiático. In: Intercom Centro-Oeste, 15., 2013, Rio Verde, GO. Anais... São Paulo: Intercom, 2013.

ROJEK, Chris. Celebridade. Rio de Janeiro: Rocco, 2008.

RONDELLI, E.; HERSCHMANN, M. A mídia e a construção do biográfico. Revista Tempo Social, São Paulo, v. 12, n. 1, p. 279-309, maio de 2000.

RUBENS, Ney. Juiz determina prisão de policial por morte de Eliza Samúdio.

Terra, Belo Horizonte, 12/07.2015. Disponível em: $<$ https://noticias.terra.com.br/brasil/policia/caso-bruno-juiz-determina-prisaode-policial-morte-de-elizasamudio,1e086e52632380d4ced27be93c9bf5d5duolRCRD.html> .

SARMENTO, Rayza; MENDONÇA, Ricardo Fabrino. Luana, Eliza e a lei Maria da Penha: o acontecimento em discussão. In: ANPOCS, 37., 2013, Águas de Lindóia, SP. Anais... Águas de Lindóia, SP: 2013.

SILVA, Maria Terezinha da. A constituição simbólica de um acontecimento: análise do processo de individualização do Mensalão. 2011, 221f. Tese (Doutorado em Comunicação Social) - Programa de Pós-graduação em Comunicação Social, Universidade Federal de Minas Gerais, Belo Horizonte, 2011.

SIMÕES, Paula Guimarães. O acontecimento Ronaldo: a imagem pública de uma celebridade no contexto social contemporâneo. 2012, 282f. Tese 


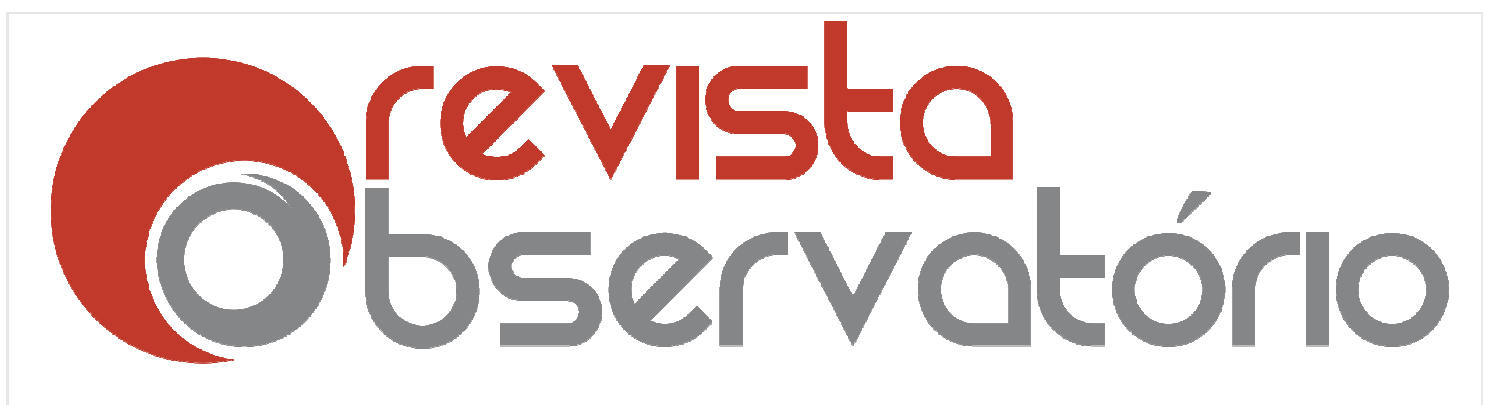

(Doutorado em Comunicação Social) - Faculdade de Filosofia e Ciências Humanas, Universidade Federal de Minas Gerais, Belo Horizonte, 2012.

SIMÕES, Paula Guimarães. Da morte consumada à morte vivida: mídia, acontecimento e figuras públicas. In: COMPOS, 24., 2015, Brasília. Disponível em: $\quad$ http://www.compos.org.br/biblioteca/textofinalcompos2015_2800.pdf. Acesso em: maio/2015.

VAZ, Andrea Cristiane. Tudo pela Fama: idealizações narcísicas na contemporaneidade. Disponível em: <http://hdl.handle.net/10482/3546>. Acesso em 13/03/2015. 2006.

VOVELLE, Michel. Ideologias e Mentalidades. São Paulo: Brasiliense, 1987. 